\title{
Deepwater Horizon oil-residues as tracers of subsurface transport, partitioning, and fate of toxic compounds in the Gulf of Mexico
}

\author{
ISABEL C. ROMERO ${ }^{*}$, JEFF P. CHANTON ${ }^{2}$, GREGG R. \\ BROOKS $^{3}$, SAMANTHA BOSMAN ${ }^{2}$, REBEKKA A. \\ LARSON $^{3}$, ARNE DIERCKS $^{4_{123}}$ \\ ${ }^{1}$ University of South Florida, St. Petersburg, FL \\ (* correspondence: isabelromero@mail.usf.edu) \\ 2 Florida State University, Department of Earth, \\ Ocean and Atmospheric Sciences, Tallahassee, FL \\ 3 Eckerd College, St. Petersburg, FL \\ ${ }^{4}$ University of Southern Mississippi, School of \\ Ocean Sciences and Engineering, Stennis Space \\ Center, MS
}

The Deepwater Horizon (DWH) is the largest accidental spill in history, with $\sim 4$ million barrels of oil released beneath the ocean's surface in the Gulf of Mexico (GoM). Following the DWH blowout, the formation of an unexpected and extended sedimentation event of oil-residues associated with marine snow and/or particles occurred over an extensive area of the seafloor $\left(\sim 11,0000 \mathrm{~km}^{2}\right)$ with deep to shallow communities exposed to high levels of toxic compounds. We investigated the distribution of hydrocarbons (e.g., polycyclic aromatic hydrocarbons, hopanes, steranes) over a large spatial and temporal scale. Results indicate that as a consequence of the portioning of oil-residues at depth, most oil-derived toxic compounds were deposited offshore (depths $>200 \mathrm{~m}$ ). Also, weathered oil residues are still present 8 -years after the spill, and are distributed relative to seafloor topography and physical processes (e.g., resuspension). Altogether, results suggest a long-term fate of oil residues in the marine environment, critical for explaining the decline of multiple deep-sea taxa in the GoM, years after the DWH. 